\title{
Um levantamento de práticas e ferramentas usadas para aumentar o nível de Cultura Digital nas escolas
}

\author{
Gilvaneide Francisca Gomes ${ }^{1}$, Ricardo André Cavalcante de Souza ${ }^{1,2}$ \\ ${ }^{1}$ Programa de Pós-Graduação em Informática Aplicada (PPGIA) \\ ${ }^{2}$ Departamento de Computação (DC) \\ Universidade Federal Rural de Pernambuco (UFRPE) \\ gilvaneidegomes27@gmail.com, ricardo.souza@ufrpe.br
}

\begin{abstract}
Digital Culture involves the transformation of social, educational and work relationships through digital technologies. The digital culture of a school is crucial to empower students with the necessary skills to face the learning and work challenges of the 21 st century. This work presents a survey of practices and tools that can be used to increase the level of Digital Culture in schools from a systematic literature mapping.

Resumo. A Cultura Digital envolve a transformação das relações sociais, educacionais e de trabalho por meio das tecnologias digitais. A Cultura Digital de uma escola é determinante para capacitar os estudantes com as habilidades necessárias para enfrentar os desafios do aprendizado e trabalho do século XXI. Este trabalho apresenta um levantamento de práticas e ferramentas que podem ser usadas para aumentar o nível de Cultura Digital nas escolas, a partir de um mapeamento sistemático da literatura.
\end{abstract}

\section{Introdução}

Cultura digital remete às relações humanas fortemente mediadas por tecnologias e comunicações por meio digital, aproximando-se de outros conceitos como sociedade da informação, cibercultura e revolução digital [CIEB, 2018]. Enquanto mediação, a cultura digital é apenas cúmplice da denominada sociedade em rede ou sociedade da informação. A Cultura Digital envolve toda a dinâmica que se processa na prática social [BUZATO, 2010].

A Base Nacional Comum Curricular (BNCC) [MEC, 2018] destaca que a Cultura Digital promove mudanças sociais significativas nas sociedades contemporâneas, preocupa-se com os conhecimentos relacionados às novas formas de comunicação e relacionamento que fazem parte do dia a dia de um cidadão do século XXI, e considera ainda questões relacionadas ao uso indevido das novas plataformas digitais em diversos ambientes e a utilização das plataformas digitais em trabalhos coletivos, visando o engajamento dos jovens na construção de soluções para os mais diversos problemas da sociedade contemporânea.

De acordo com o Currículo de Referência em Tecnologia e Computação [CIEB, 2018], à Cultura Digital estão associados os seguintes conceitos: Letramento Digital, trata da comunicação verbal e escrita por meio de dispositivos digitais e aborda o desenvolvimento de habilidades relacionadas ao uso destes e softwares associados a eles com proficiência; Cidadania Digital, trata do uso responsável e ético da tecnologia pelas pessoas, envolvendo o acesso, direito e proteção e segurança digital; e Tecnologia e Sociedade, trata dos avanços tecnológicos e dos associados desafios às pessoas, aborda como a tecnologia transforma as formas de trabalhar, decidir, pensar e viver. 
A Cultura Digital relaciona-se, portanto, em como as tecnologias digitais transformam, dão suporte e habilitam as relações sociais, educacionais e de trabalho do século XXI. A escola como instituição formadora precisa fomentar e fortalecer uma Cultura Digital de modo a equipar os estudantes (futuros trabalhadores) com as competências digitais necessárias para tratar dos desafios do século XXI. Preocupa o fato de que a escola continua praticamente intocável em seu modo de organizar o ensinar e aprender, embora a tecnologia digital tenha dimensão cada vez mais significativa na vida das pessoas, especialmente dos mais jovens, considerados nativos digitais [Buckingham, 2010]. Os modos de organizar a escola opõem-se, frontalmente, aos modos pelos quais a denominada cultura digital reconfigura não apenas recursos educacionais, mas, sobretudo, os modos pelos quais nos relacionamos [Alonso, 2017].

As competências digitais que levam os estudantes a alcançar um nível apropriado de Cultura Digital tornam-se ainda mais relevantes e necessárias tendo em vista as restrições de tempo e espaço físico impostas pelo sistema educacional tradicional fortemente afetado pela pandemia do Covid19. De acordo com a UNESCO [2020], "Cerca de 190 países em todo o mundo fecharam suas escolas e universidades para impedir a propagação do coronavírus. Isso obrigou cerca de 1,5 bilhão de estudantes a ficar em casa".

Diante deste cenário, este trabalho apresenta um levantamento de práticas e ferramentas usadas para aumentar o nível da Cultura Digital nas escolas, resultante de um mapeamento sistemático da literatura especializada. Entende-se por prática uma maneira comprovada de realizar um trabalho para resolver um ou mais problemas que ocorrem comumente, já por ferramenta uma capacidade, automatizada ou não, que dá suporte a realização de um trabalho [OMG, 2008].

\section{Mapeamento Sistemático da Literatura}

O processo de mapeamento sistemático da literatura, baseado na abordagem proposta por Petersen et al. (2008), consiste das seguintes etapas: Definição do escopo do mapeamento da literatura, para definição das bases de pesquisa, período de publicação dos estudos primários e questão de pesquisa; Busca por estudos primários, para definição da string de busca para direcionar consulta às bases de pesquisa; Extração de dados, para seleção a partir da análise do título e resumo dos estudos primários retornados; e Análise e síntese dos resultados, para leitura completa e análise qualitativa dos estudos primários e síntese daqueles que contribuem com a resposta à questão de pesquisa formulada. A Tabela 1 apresenta o resumo dos resultados de cada etapa do mapeamento da literatura.

Tabela 1. Síntese do Mapeamento Sistemático da Literatura

\begin{tabular}{|c|l|}
\hline Etapa & Resultado \\
\hline $\begin{array}{c}\text { Definição do escopo do } \\
\text { mapeamento }\end{array}$ & $\begin{array}{l}\text { ACM, Scopus. } \\
\text { Período de Publicação: } 2015 \text { a } 2019 \\
\text { Questão de pesquisa: quais fatores usados para habilitar, levar à e } \\
\text { mensurar/avaliar Cultura Digital? }\end{array}$ \\
\hline $\begin{array}{c}\text { Busca por estudos } \\
\text { primários }\end{array}$ & $\begin{array}{l}\text { String de buscaeminglês: (indicator OR measurement OR evaluation } \\
\text { OR driver) AND ("digital literacy" OR "digital culture" OR "digital } \\
\text { society" OR "digital citizenship") }\end{array}$ \\
\hline
\end{tabular}




\begin{tabular}{|c|l|}
\hline \multirow{3}{*}{ Extração dos dados } & $\begin{array}{l}\text { String de busca em português:(indicador OR mensuração OR } \\
\text { avaliação OR determinante) AND ("letramento digital" OR "cultura } \\
\text { digital" OR "sociedade digital" OR "cidadania digital") }\end{array}$ \\
\hline $\begin{array}{l}\text { Quantidade de artigos retornados após a busca: 111 } \\
\text { Quantidade de artigos selecionados após análise do título e } \\
\text { resumo: 37. }\end{array}$ \\
\hline $\begin{array}{c}\text { Análise e síntese dos } \\
\text { resultados }\end{array}$ & $\begin{array}{l}\text { Critérios Qualitativos: CQ1 - o estudo trata de conceitos associados } \\
\text { à cultura digital; e CQ2 - o estudo trata práticas ou ferramentas que } \\
\text { habilitam, determinam ou mensuram/avaliam a Cultura Digital. } \\
\text { Quantidade de estudos primários que atenderam os critérios } \\
\text { qualitativos CQ1 e CQ2: } 211 \text {. }\end{array}$ \\
\hline
\end{tabular}

\section{Resultados e Discussões}

A Tabela 2 apresenta uma síntese das temáticas encontradas no mapeamento da literatura. Vale ressaltar que um artigo pode tratar de mais de uma temática. As temáticas explicitadas no mapeamento da literatura estão associadas às práticas e ferramentas usadas para aumentar o nível de Cultura Digital nas escolas.

Tabela 2. Síntese das Temáticas Abordadas

\begin{tabular}{|c|l|l|}
\hline $\begin{array}{c}\text { Quantidade } \\
\text { de Artigos }\end{array}$ & Temática Abordada & Descrição \\
\hline 04 & Artefatos digitais & $\begin{array}{l}\text { Construção e manutenção de artefatos digitais físicos } \\
\text { (hardware), e lógicos (software), usados no processo de } \\
\text { ensino-aprendizagem. }\end{array}$ \\
\hline 16 & Conceituação & $\begin{array}{l}\text { Análise e discussão de conceitos relacionados à Cultura } \\
\text { Digital, identificação de limitantes e propostas de melhorias. } \\
\text { Tais conceitos podem ser utilizados em capacitações. }\end{array}$ \\
\hline 02 & Habilidades digitais & $\begin{array}{l}\text { Desenvolvimento de abordagens para fomentar e avaliar } \\
\text { habilidades digitais. }\end{array}$ \\
\hline 13 & Maturidade digital & $\begin{array}{l}\text { Avaliação e mensuração do nível de maturidade digital de um } \\
\text { indivíduo ou organização. }\end{array}$ \\
\hline 02 & $\begin{array}{l}\text { Processos centrados } \\
\text { no indivíduo }\end{array}$ & $\begin{array}{l}\text { Execução de processos centrados na perspectiva dos } \\
\text { indivíduos para diagnosticar necessidades e prover soluções } \\
\text { para promover os conceitos associados à Cultura Digital. }\end{array}$ \\
\hline 08 & produtos digitais de & $\begin{array}{l}\text { Desenvolvimento de produtos digitais de propósito específico } \\
\text { para aprimorar a Cultura Digital, tal como jogos digitais para } \\
\text { estimular práticas de Cidadania Digital. }\end{array}$ \\
\hline
\end{tabular}

A Figura 1 consiste em um Gráfico de Bolhas que apresenta uma visualização gráfica do resultado do mapeamento da literatura. No eixo horizontal estão as temáticas (Tabela 2) tratadas

\footnotetext{
${ }^{1}$ As referências completas podem ser consultadas em: EstudosPrimáriosAceitos
} 
nos estudos analisados. No eixo vertical estão a Cultura Digital e os conceitos relacionados (Letramento Digital, Cidadania Digital, e Sociedade Digital. O gráfico mostra a quantidade de estudos relacionados à uma temática específica relacionada à Cultura Digital como um todo ou a um dos conceitos específicos associados.

A questão de pesquisa (RQ) que orientou a execução do mapeamento da literatura foi: “quais fatores usados para habilitar, levar à e mensurar/avaliar Cultura Digital?". A partir dos resultados encontrados é possível considerar que as ferramentas podem ser usadas para "habilitar" e "mensurar/avaliar" à Cultura Digital ou algum conceito específico associado; e as práticas são determinantes para "levar à" melhoria da Cultura Digital nas escolas.

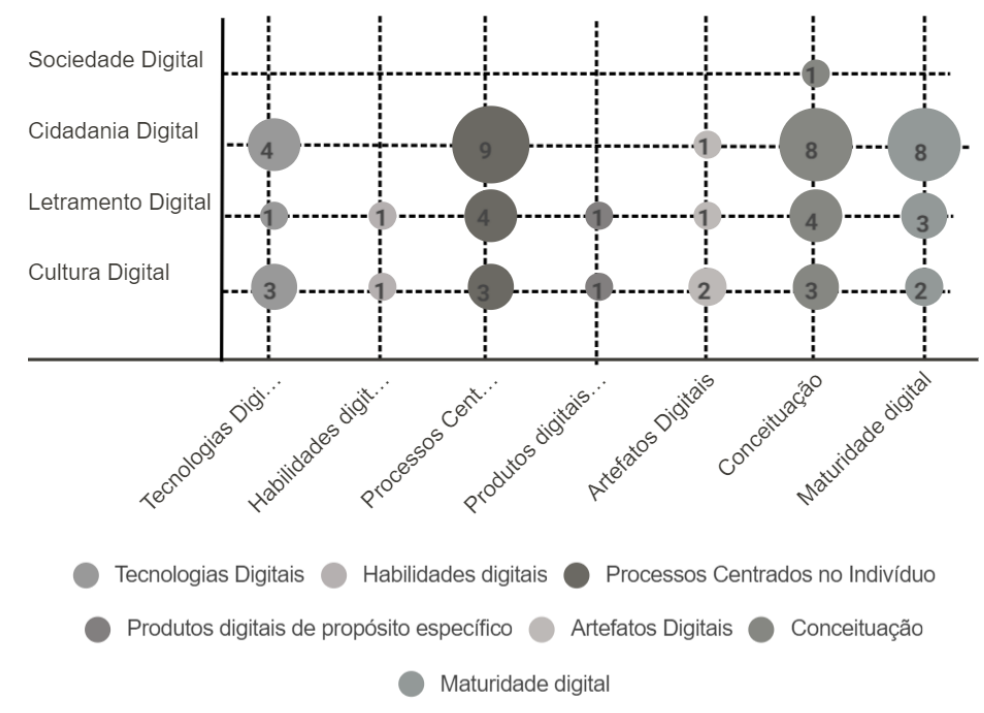

Figura 1. Resultado quantitativo do Mapeamento da Literatura

As ferramentas encontradas foram: Artefatos digitais, usados no processo de ensinoaprendizagem para prover aos estudantes conhecimento prático de "como montar/manter" hardwares e como desenvolver softwares; Produtos digitais de propósito específico, usados para prover conhecimento específico ou estimular habilidades para melhorar a Cultura Digital de um indivíduo, tais como softwares de verificação de "fake news"; e Tecnologias digitais, usadas para tornar o processo de ensino-aprendizagem descentralizado, dinâmico e personalizado. Já as práticas encontradas foram: Conceituação, meio de prover a internalização pelos estudantes de conceitos necessários ao entendimento pleno de Cultura Digital; Habilidades digitais, meios de equipar os estudantes com habilidades e competências necessárias para o aprendizado e trabalho do século XXI ; Maturidade digital, meios para mensurar e avaliar o nível de maturidade digital de um estudante, sala de aula ou escola; e Processos centrados no indivíduo, meios de desenhar e desenvolver soluções para aumentar o nível de Cultura Digital a partir das reais necessidades e perspectivas dos estudantes.

\section{Conclusão}

Este trabalho apresentou um levantamento de práticas e ferramentas que podem ser usadas para aumentar o nível de Cultura Digital nas escolas, resultante de um mapeamento sistemático da literatura. As práticas consistem em meios documentados de fazer um trabalho, já as ferramentas são usadas para auxiliar a execução de um trabalho. O nível da Cultura Digital refere-se a quão as tecnologias digitais influenciam e transformam as relações sociais, educacionais e de trabalho. 
O mapeamento da literatura mostra que os estudos analisados tratam de temáticas relacionadas à Cultura Digital como um todo ou especificamente a um dos conceitos associados: Letramento Digital, que envolve a comunicação digital e a proficiência no uso de equipamentos e produtos digitais; Cidadania Digital, que envolve o uso ético, responsável e seguro das tecnologias digitais; e Sociedade Digital, que trata das relações sociais mediadas por tecnologias digitais e desafios associados. Ao final foi possível levantar, a partir da análise das temáticas encontradas nos estudos analisados, algumas práticas e métodos para aumentar o nível da Cultura Digital nas escolas. As práticas levantadas foram: Capacitações, Habilidades digitais, Maturidade digital, e Processos centrados no indivíduo. Já as ferramentas foram: Artefatos Digitais, Produtos digitais de propósito específico, e Tecnologias digitais.

Como oportunidades de trabalhos futuros, podemos citar: o desenvolvimento de uma abordagem para avaliar o nível de Cultura Digital de um estudante, escola ou processo de ensinoaprendizagem a partir de indicadores pré-estabelecidos; aplicação do paradigma de transformação digital para repensar a Cultura Digital nas escolas; e desenvolvimento de uma abordagem prática para dar suporte em equipar os estudantes com as competências digitais necessárias para o alcance dos componentes relacionados a Cultura Digital, tal como, a cidadania digital e o letramento digital.

\section{Referências}

Alonso, K. (2017). Cultura digital e formação: entre um devir e realidades pungentes. Formação de educadores na cultura digital: a construção coletiva de uma proposta. Florianópolis: UFSC /CED/NUP, 625p.

Buckingham, D. (2003). Media Education: literacy, learning and contemporary culture. Cambridge: Polity.

Buzato, M. (2010). Cultura digital, Educação e Letramento: conflitos, desafios, perspectivas In: HÖFLING, C. (Org.). Jornada de Letras. São Carlos: Editora da UFSCar, p. 69-88.

CIEB - Centro de Inovação para a Educação Brasileira. (2018). Currículo de Referência em Tecnologia e Computação: da educação infantil ao ensino fundamental. Disponível em http://curriculo.cieb.net.br/

MEC - Ministério da Educação. (2018). Base Nacional Comum Curricular (BNCC): educação é a base.

OMG. (2008). SPEM 2.0 - Software \& Systems Process Engineering Metamodel. Disponível em: http://www.omg.org/spec/SPEM/About-SPEM/

Petersen, K.; Feldt, R.; Mujtaba, S.; Mattsson, M. (2008) Systematic Mapping Studies in Software Engineering. 12th International Conference on Evaluation and Assessment in Software Engineering (EASE). Universityof Bari, Italy.

UNESCO. COVID-19: conte à UNESCO como você está lidando com o fechamento das escolas. Disponível em: https://bit.ly/3i6a7k1Acessado em: 27 de Junho de 2020. 